TAPROBANICA, ISSN 1800-427X. November, 2020. Vol. 09, No. 02: pp. 133-135.

(C) Research Center for Climate Change and Department of Biology, Faculty of Mathematics \& Natural Sciences, University of Indonesia, Depok 16424, INDONESIA.

http://www.taprobanica.org/

https://doi.org/10.47605/tapro.v9i2.227

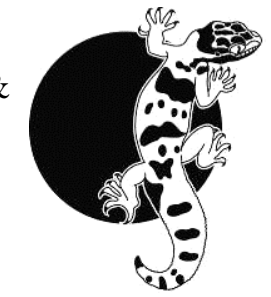

\title{
Cladonotus bhaskari: a call for improving ethical standards in taxonomic journals
}

We are in a period of mass extinctions, when many species of animals, plants and other organisms are disappearing through direct or indirect human activities. Yet, the declining numbers of expert taxonomists represents a barrier to identifying, studying and protecting threatened species (Wilson 2005). This is especially true in developing countries such as Sri Lanka. 'How can we enjoy and protect something if we don't know it is out there to enjoy and protect?' (Evenhuis 2007).

As urgent as the description of newly discovered species is, such descriptions must necessarily take place in the context not only of the International Code of Zoological Nomenclature (ICZN 1999, hereafter the Code) but also a sound ethical framework including adherence to local laws. Even urgently needed taxonomic research cannot be justified if it breaches ethical guidelines or the laws of the countries in which the organisms of interest originate, as the following cases illustrate.

A new species epithet "Cladonotus bhaskari" (Orthoptera: Tetrigidae: Cladonotini) was recently erected to describe a Sri Lankan twighopper, and the description was published by Tumbrinck, Deranja, Adžic, Pavlovic and Skejo in the journal Zootaxa, volume 4821, Number 2 on 31 July 2020. The authors based their description (pp. 337-340 in that publication) on a single female specimen (holotype) collected from Sinharaja rainforest, Sabaragamawa, Sri Lanka, and claimed that the holotype is deposited in Museum Koenig in Bonn, Germany (ZFMK). The authors were, however, unable to provide any catalogue number for the holotype (Tumbrinck et al. 2020). Given this omission I suspected that the holotype may not have been deposited at the ZFMK. On 12 September 2020, I contacted Prof. Dr. Bernhard Misof, Director, Zoological Research Museum (Museum Koenig in Bonn, ZFMK), Adenauerallee 160, 53113 Bonn to investigate whether the holotype of Cladonotus bhaskari is actually deposited at ZFMK. On 16 September 2020, Prof. Misof replied "we have checked in our collection and do not have this holotype, as you suspected already. This also explains why there is no designated catalogue number in the publication". Hence, the epithet Cladonotus bhaskari was based on an unavailable specimen.

In this case a holotype has been fixed but it is currently not in the collection where it is intended to be deposited. It is a common situation that it takes some considerable time after the description before a specimen gets deposited in its intended repository. Normally, specimens end up where they are stated to be deposited. Considering this reality, the Code only requires "a statement of intent" to deposit the type specimen in a collection, not that it is actually deposited; i.e. just a statement of typedesignation indicating the name and location of the collection (see Art. 16, Section 4, Number 2 of the Code). In this case it is intended to deposit the holotype at ZFMK (but currently it is not available at ZFMK), hence the nomen Cladonotus bhaskari is available and valid. Also there are a large number of cases where types have been lost between description and deposition, but the names affected remain available. In this case, if this specimen cannot be found, then the type is considered lost, at least until it can be located, assuming it does still exist. In cases of necessity, if the holotype specimen in question is missing, the neotype could be designated.

There are certainly some ill-intentioned authors, who state a repository fraudulently, but these are rare exceptions. Recently, the Director General of the Department of Wildlife Conservation in Sri Lanka (hereafter DWC), reported in Silumina, a local newspaper in the Sinhala language, that the nomen Cladonotus bhaskari was based on a smuggled specimen. In the original description, the authors stated that the holotype was collected on 16 November 2016, but did not provide the numbers 
of any permits to collect the specimen (holotype) from Sinharaja rainforest, Sri Lanka, which is a Protected Forest Reserve and also a UNESCO World Heritage site. The original description also implies that the authors received the specimen directly from the collector (see the Acknowledgement in Tumbrinck et al. 2020), but they failed to provide any collecting and international transporting permits in the acknowledgements, which is necessary for specimens that have been intended to be deposited at any institute.

On the other hand, even though the authors were unable to provide any legal permit in their publication, following the principle of international human rights the authors are "innocent until proven guilty". Therefore, the DWC must prove that the collection of the holotype was not permitted and that it was smuggled out of Sri Lanka. While researchers must strive to work with legally collected material, it is not always possible to trace the paper trail. Therefore, the authors are innocent until proven guilty. Neither DWC nor DWC affiliated legal advisors in the National Research Committee responded to my official request (since 01 September 2020) for information on the state of the permit for the holotype of Cladonotus bhaskari. If the DWC is unable to prove the claimed illegal status of the holotype, the local newspaper reports have to be considered as a serious attempt to defame reputable researchers, in this case Tumbrinck et al. 2020 vs. DWC.

There have been several recent cases of new species having been described from freshly collected specimens that were suspected of being either collected or exported illegally due to the noninvolvement of local researchers and the non-declaration of collecting and transporting permits; among them new spiders (Pholcus sp., Wanniyala sp.), damselflies (Ceylonosticta sp.), and even mites (Cosmolaelaps sp., Piona sp., Neumania sp., Krendowskia sp., Mideopsis sp.). See Bedjanič et al. (2016), Dong et al. (2016), Joharchi et al. (2020), Li \& Yin (2020), Xin et al. (2020), and Zawal et al. (2020).

Why does all this matter? Because the hype surrounding the 1992 Convention on Biological Diversity instilled in many biodiversity-rich developing countries the illusion that biodiversity is a monetisable economic resource (Pethiyagoda 2004, Pethiyagoda et al. 2007). The 2014 Nagoya Protocol strengthened this illusion still further. In response, many biodiversity-rich nations introduced draconian legislation to protect their biodiversity, critically, including protection from scientific investigation by their own nationals (Prathapan et al. 2018). As a result, an iron curtain has descended between biodiversity researchers on the one hand and the resources they seek to conserve, on the other. Now, even as local researchers are hamstrung, a new breed of 'scientific collectors' from the developed world is making the rounds of poor countries, disguised as tourists, illegally collecting and smuggling specimens. This brings science into disrepute. The consequence is that all scientistsespecially the local ones who do most of the heavy lifting - are treated with increased suspicion by conservation regulators, stifling urgently-needed biodiversity research still further.

How can the scientific community do better? Most of these new species descriptions were published in professional journals such as Zootaxa, which have a duty of care to ensure that they only publish work that meets the ethical and legal obligations of their field. Clearly, journal editors and reviewers cannot be compelled to police scientific misconduct. One possibility, however, is to require submitting authors to make a statement that to the best of their knowledge, type material designated by them that originates from a third country has been legally collected and exported. Many journals require statements of this kind regarding the ethical treatment of animals and conflicts of interest. However, when it comes to pirated specimens, the community of zoological taxonomists has been largely silent. This needs to change. A small number of delinquent 'scientific collectors' and taxonomists must not be allowed to bring the entire scientific community into disrepute, placing yet another obstacle in the path of documenting Earth's dwindling biodiversity.

However, once they are validly published sensu the Code, retractions have no effect on the availability of names. Therefore, I do not argue for journals to retract the publications, in this case the publication in Zootaxa, because retractions only cause confusion, and the names still remain available. As there is no requirement in the Code for verification of the physical placement of the type specimen, it does not matter if the material used was either authorised or smuggled (even currently invisible in this case). Therefore, it is also the responsibility of the institutions where deposits are made not to accept any smuggled specimens. Regarding the physical deposition of the holotype of Cladonotus bhaskari, if the specimen does turn up in Germany, it is advisable that it be transferred to one of the Sri Lankan museums for permanent safe keeping. Otherwise, it clearly violates the rules 
and regulations of Sri Lanka: Fauna \& Flora Protection Ordinance (Chapter 469), Customs Ordinance (Chapter 235), Forest Conservation Ordinance (Chapter 451), National Heritage Wilderness Areas Act, No. 3 of 1988 etc., and international agreements such as the Nagoya Protocol in case of any genetic material extracts from the specimen.

Note: An earlier version of this draft was emailed to the authors of Bedjanič et al. (2016), Dong et al. (2016), Joharchi et al. (2020), Li \& Yin (2020), Xin et al. (2020), and Zawal et al. (2020) with an invitation to respond with objections, corrections or comments, which would be considered for publication; none of them responded.

\section{Acknowledgements}

I thank Prof. Dr. Bernhard Misof, Director Zoological Research Museum (ZFMK) for his support in confirming the unavailability of the specimen at ZFMK. Also I thank Dr. Neal L. Evenhuis (Bishop Museum, Honolulu, Hawaii), Dr. Frank-Thorsten Krell (Denver Museum of Nature \& Science, Colorado), Dr. Doug Yanega (Entomology Research Museum, University of California), Dr. Dmitry Dmitriev (Illinois Natural History Survey), Dr. Alberto Ballerio (Milano), Prof. Vincent Nijman (Oxford Brookes University, Oxford), Prof. Aaron M. Bauer (Villanova University, Pennsylvania), Prof. Chris Margules (James Cook University, Queensland), Philip Bowles (CI-IUCN Biodiversity Assessment Unit, Washington DC), and an anonymous reviewer for informative discussions and/or for providing critical comments (not necessarily agreeing with it) on this editorial.

\section{Literature cited}

Bedjanič, M., K. Conniff, R.A. Dow, F.R. Stokvis, R. Verovnik, and J. van Tol (2016). Taxonomy and molecular phylogeny of the Platystictidae of Sri Lanka (Insecta: Odonata). Zootaxa, 4182 (1): 1-80.

Dong, T., G. Zheng, Z. Yao, and S. Li (2016). Fifteen new species of the spider genus Pholcus (Araneae, Pholcidae) from Southeast Asia. Zootaxa, 4136 (2): 201-246.

Evenhuis, N.L. (2007). Helping solve the "Other" Taxonomic Impediment: Completing the Eight Steps to Total Enlightenment and Taxonomic Nirvana. Zootaxa: 1407: 3-12.

ICZN (1999). International Code of Zoological Nomenclature, 4th edition. International Trust for Zoological Nomenclature, London: 306pp.

Joharchi, O., S.G. Ermilov, and A.A. Khaustov (2020). Two new species of Cosmolaelaps Berlese (Acari: Laelapidae) from Sri Lanka. Zootaxa, 4743 (2): 151-166.

Li, N. and Z.-W. Yin (2020). The first Sri Lankan species of Labomimus Sharp (Coleoptera: Staphylinidae: Pselaphinae). Zootaxa, 4809 (2): 397-400.

Pethiyagoda, R. (2004). Biodiversity law has had some unintended effects. Nature, 429: 129.

Pethiyagoda, R., N. Gunatilleke, M. De Silva, S. Kotagama, S. Gunatilleke et al. (2007). Science and biodiversity: the predicament of Sri Lanka. Current Science, 92: 426-427.

Prathapan, K.D., R. Pethiyagoda, K.S. Bawa, P.H. Raven, and P.D. Rajan (2018). When the cure killsCBD limits biodiversity research. Science, 360 (6396): 1405-1406.

Silumina (2020). The Latest Victim of Bio-theft. Silumina New Paper Sri Lanka [in Sinhala language]. Archived in <https://archive.org/details/silumina-13-sept-2020>

Tumbrinck, J., M. Deranja, K. Adžic, M. Pavlovic, and J. Skejo (2020). Cockscomb-shaped twighopper, Cladonotus bhaskari sp. n., a new and rare pygmy grasshopper species from Sri Lanka (Orthoptera: Tetrigidae: Cladonotinae). Zootaxa, 4821 (2): 333-342.

Wilson, E.O. (2005). Systematics and future of Biology. PNAS, 102: 6520-6521.

Xin, Y., Z. Yao, and S. Li (2020). Two new species of the spider genus Wanniyala Huber \& Benjamin, 2005 (Araneae: Pholcidae) from Sri Lanka. Zootaxa, 4759 (4): 566-574.

Zawal, A., I. Szucko, M. Szenejko, L. Skuza, and A. Bankowska (2020). New records of water mites (Acari: Hydrachnidia) from Sri Lanka with description of four new species and some remarks of relationships. Systematics \& Applied Acarology, 25 (9): 1589 - 1610.

A.A. Thasun Amarasinghe

Co-Editor-in-Chief: Taprobanica, the journal of Asian Biodiversity

November $28^{\text {th }}, 2020$ 